\title{
Effect of Wind Generation System Rating on Transient Dynamic Performance of the Micro-Grid during Islanding Mode
}

\author{
Rashad M. Kamel, Aymen Chaouachi, Ken Nagasaka \\ Environmental Energy Engineering, Department of Electronics \& Information Engineering, Tokyo University of Agriculture and \\ Technology, Tokyo, Japan. \\ Email:r_m_kamel@yahoo.com, a.chaouachi@gmail.com,bahman@cc.tuat.ac.jp
}

Received August $3^{\text {rd }}, 2010$; revised October $8^{\text {th }}, 2010$; accepted October $11^{\text {th }}, 2010$.

\begin{abstract}
Recently, several types of distributed generations (DGs) are connected together and form a small power system called Micro Grid $(M G)$. This paper developed a complete model which can simulate in details the transient dynamic performance of the MG during and subsequent to islanding process. All MG's components are modeled in detail. The developed model is used to investigate how the transient dynamic performance of the MG will affected by increasing the rating of wind generation system installed in the MG. Two cases are studied; the first case investigates the dynamic performance of the MG equipped with $10 \mathrm{~kW}$ fixed speed wind generation system. The second studied case indicates how the dynamic performance of the $M G$ will be affected if the wind generation system rating increases to $30 \mathrm{~kW}$. The results showed that increasing of wind generation rating on the MG causes more voltage drops and more frequency fluctuations due to the fluctuation of wind speed. Increasing voltage drops because wind turbine generator is a squirrel cage induction generator and absorbs more reactive power when the generated active power increases. The frequency fluctuations due to power fluctuations of wind turbine as results of wind speed variations. The results proved that when the MG equipped with large wind generation system, high amount of reactive power must be injected in the system to keep its stability. The developed model was built in Matlab ${ }^{\circledR}$ Simulink ${ }^{\circledR}$ environment.
\end{abstract}

Keywords: $M G$, Distributed Generators, Wind Power Rating and Dynamic Performance

\section{Introduction}

Recent technological developments in micro generation domain, necessity of reducing $\mathrm{CO}_{2}$ emissions in the electricity generation field, and electricity business restructing are the main factors responsible for the growing interest in the use of micro generation [1,2]. In fact the connection of small generation units - the micro sources (MS), with power rating less than a few tens of kilowattsto low voltage (LV) networks potentially increases the reliability to final consumers and brings additional benefits for global system operation and planning, namely, regarding investment reduction for future grid reinforcement and expansion [3].

In this context, a MG can be defined as a LV network (e.g. a small urban area, a shopping center, or an industrial park) plus its loads and several small modular generation systems connected to it, providing both power and heat to local loads [combined heat and power (CHP)]
[3]. The MG is intended to operate in the following two different operating conditions:

- Normal Interconnected Mode: MG is connected to a main grid (distribution network), either being supplied by it or injecting some mount of power into the main system.

- Emergency Mode: MG operates autonomously, in a similar way to physical islands, when the disconnection from the upstream distribution network occurs.

The development of MGs can contribute to the reduction of emissions and the mitigation of climate changes. This is because available and currently developing technologies for distributed generation units are based on renewable sources and micro sources that are characterized by very low emissions [4]. The new micro sources technologies (e.g. micro gas turbine, fuel cells, photovoltaic panels and several kinds of wind turbines) used in $\mathrm{MG}$ are not suitable for supplying energy to the MG directly 
[3]. They have to be interfaced with the MG through an inverter stage. Thus, the use of power electronic interfaces in the MG leads to a series of challenges in the design and operation of the MG [5]. Technical challenges associated with the operation and control of MG are immense. Ensuring stable operation during network disturbances, maintaining stability and power quality in the islanding mode of operation requires the development of sophisticated control strategies for MG's inverters in order to provide stable frequency and voltage in the presence of arbitrarily varying loads. This paper's objective is to demonstrate the transient dynamic performance of the MG during and subsequent to islanding process and how it will affected with increasing the wind power rating installed in the MG.

Reference [6] discusses MG autonomous operation during and subsequent to islanding process but the renewable micro sources not included, also, this reference used $\mathrm{PSCAD/EMTDC}$ package for analysis. In references [7] and [8] a control scheme based on droop concepts to operate inverter feeding a standalone AC system is discussed. References [9] and [10] discuss the behavior of distributed generators (DGs) connected to distribution network, however, the dynamics of the primary energy sources has not been considered, not allowing obtaining the full picture of the MG long-term dynamic behavior, which is largely influenced by the micro sources dynamic.

This paper developed a complete model to simulate the dynamic performance of the MG. All MG's components are modeled in details. The developed model is a general and can be used to study any disturbance which may occur in the MG. Effect of increasing wind power rating is investigated. Two cases are studied; the first case is studying the transient dynamic performance of the MG equipped with $10 \mathrm{~kW}$ fixed speed wind generation system. The second case is how the dynamic performance of the MG will affect when the wind generation system is increased to $30 \mathrm{~kW}$. The developed model was built in Matlab ${ }^{\circledR}$ Simulink ${ }^{\circledR}$ environment.

To conduct the proposed studies, single line diagram of the studied MG is presented in Section 2. Section 3 gives a brief description of all MG's components developed models. Section 4 presents a description of the complete model with the applied controls. Two studied cases with results and discussions are explained in Section 5. Conclusions are presented in Section 6.

\section{Single Line Diagram of the Studied Micro-Grid}

Figure 1 shows single line diagram of the studied MG. It consists of 7 buses. Flywheel is connected to bus \# 1 . Wind generation system is connected to bus \# 2. Two

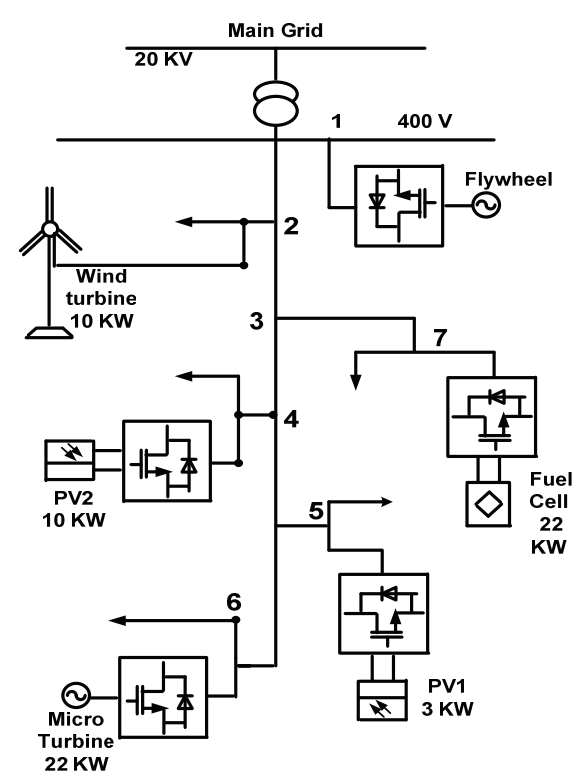

Figure 1. Single line diagram of the studied MG.

photovoltaic panels with rating $10 \mathrm{~kW}$ and $3 \mathrm{~kW}$ are connected to buses 4 and 5, respectively. Single shaft micro turbine (SSMT) with rating $22 \mathrm{~kW}$ is connected to bus \# 6. Bus 7 is provided with $22 \mathrm{~kW}$ solid oxide fuel cell (SOFC). The values loads and line parameters of the MG are available in reference [11].

\section{Description of Microgrid Individual Components Models}

\subsection{Inverter Models}

Inverters play a vital role in the system which interfaces of the micro sources with the AC power system. Two control models of the inverter which used to interface micro sources to the MG are developed. The configuration of the basic inverter interfaced micro sources is shown in Figure 2.

The inverter controls both the magnitude and phase angle of its output voltage ( $V$ in Figure 2). The vector relationship between the inverter voltage $(V)$ and the local MG voltage ( $E$ in Figure 2) along with the inductor's reactance determines the flow of active and reactive powers from the micro source to the MG [12]. The corresponding mathematical relations for $P$ (active power) and $Q$ (reactive power) magnitudes are given by the following equations:

$$
\begin{gathered}
P=\frac{V E}{\omega L} \sin \left(\delta_{V}-\delta_{E}\right) \\
Q=\frac{V^{2}}{\omega L}-\frac{V E}{\omega L} \cos \left(\delta_{V}-\delta_{E}\right)
\end{gathered}
$$

From Equation (1) and Equation (2), the control of ac- 


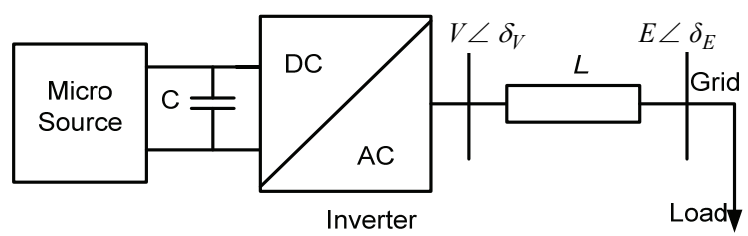

Figure 2. Basic inverter interfaced micro source.

tive and reactive powers flow reduces to the control of power angle and the inverter's voltage level, respectively.

$\mathrm{P}$ is the active (real) power (Watts) generated by micro sources (Flywheel, wind generator, fuel cell, micro turbine and photovoltaic panels). Frequency control depends on the amount of active power (P) in the Micro Grid. If $\mathrm{P}$ generated by micro sources is higher than $\mathrm{P}$ consumed by loads, frequency increase than its nominal value and vice versa.

On the other hand, Q is the reactive power (its unit is Volt Ampere Reactive VAR). The value of the reactive power can be controlled by controlling inverters which interface micro sources with the Micro Grid (MG). Voltage is controlled by controlling amount of reactive power generated in the MG.

\subsubsection{Inverter Model with PQ Controller Scheme}

The basic structure of inverter $P Q$ controller is shown in Figure 3 [8].

Active and reactive powers can be controlled independently to a good extent, then as shown in Figure 3, two Proportional Integral (PI) controllers would suffice to control the flow of active and reactive powers by generating the proper values of voltage magnitude $(V)$ and phase angle $\left(\delta_{V}\right)$ based on the instantaneous values of voltages and currents which are measured from local MG voltage $\left(E_{b u s}\right)$. If the inverter switching details are ignored, the control system will be simplified to the configuration shown in Figure 4 [12].

Inverter $P Q$ model is suitable for interfacing single shaft micro turbine, solid oxide fuel cell and photovoltaic panels. Figure 5 shows the terminal block diagram of the $P Q$ inverter developed model. The input terminals are active and reactive powers produced by the micro source, while the output terminals are the three phase terminals connected to the MG.

\subsubsection{Inverter Model with $\boldsymbol{V} \boldsymbol{f}$ Controller}

In order to develop a model for voltage-frequency controlled inverter, two control loops are needed. Frequency controller is a proportional integral (PI) controller which is driven by the frequency deviation. As shown in Figure $\mathbf{6}(\mathbf{a})$, frequency of the system can be measured by a phase locked loop (PLL), and in order to get a better performance, a feed-forward controller can be implemented. To

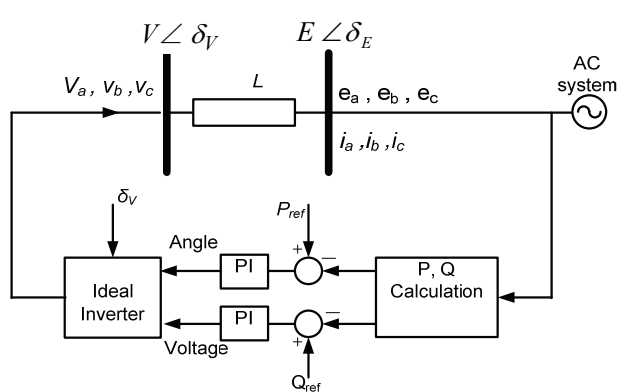

Figure 3. Basic structure of the inverter PQ control scheme.

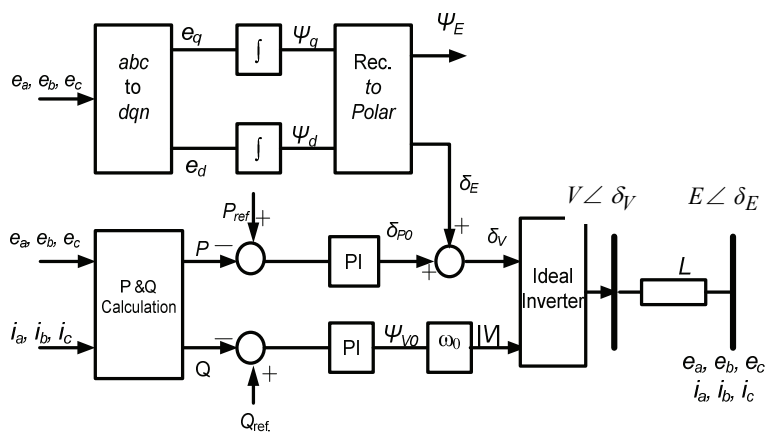

Figure 4. Simplified inverter $P Q$ control scheme.

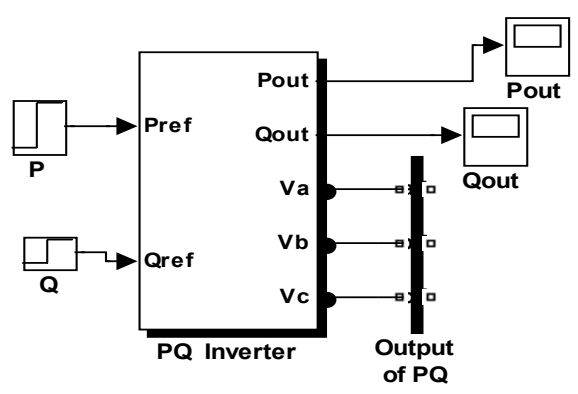

Figure 5. Inverter $P Q$ control model.

regulate the voltage, the set point (reference voltage $\mathrm{E}_{\mathrm{ref}}$ ) is compared with the measured voltage (MG voltage $E$ ) and a PI controller is responsible to generate the adequate voltage magnitude $V$ as shown in Figure 6(b) [12]. $V f$ mode is the model which keep the voltage at constant value and return the frequency to its nominal after disturbance occurring by controlling the amount of the active power injected in the MG. $V f$ inverter is used to interface the flywheel to the MG and represents the reference bus (slack bus) of the MG during and subsequent to islanding occurrence as shown in Figure 7.

\subsection{Micro Sources Models}

Detailed standalone models for micro turbine, fuel cell, wind generation system and photovoltaic panels are developed. Those models are briefly described as follows: 


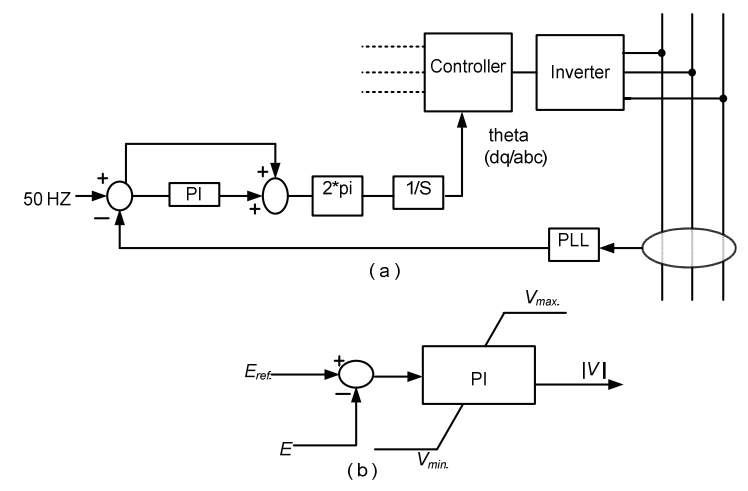

Figure 6. Inverter $V f$ control scheme.

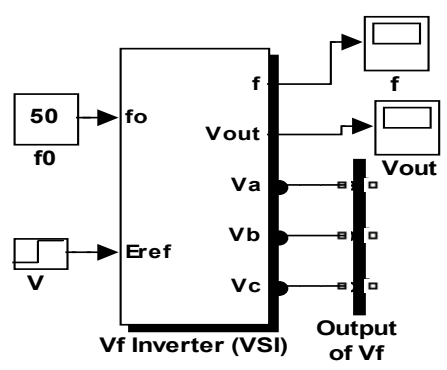

Figure 7. $V f$ controlled inverter.

\subsubsection{Single Shaft Micro Turbine Model (SSMT)}

References [13-16] describe in details the mathematical model of single shaft and split-shaft micro turbine. The mathematical model is simulated in Matlab ${ }^{\circledR}$ Simulink $^{\circledR}$ environment and the model is shown in Figure 8(a). Input terminal is $P_{\text {ref }}$ which represent the desired power. The output terminal is $P_{e}$ (electrical power output from synchronous generator which coupled with micro turbine). $P_{e}$ is connected to $P$ input terminal of the $P Q$ inverter. Load connected to the synchronous generator is a virtual resistive load because in Matlab $^{\circledR}$ Simulink $^{\circledR}$ the synchronous generator model must always connected to external load.

\subsubsection{Solid Oxide Fuel Cell (SOFC) Model}

Detailed mathematical model of solid oxide fuel cell (SOFC) is discussed by references $[13,14,17]$. This model is simulated using Matlab ${ }^{\circledR}$ Simulink $^{\circledR}$ and model block diagram is shown in Figure 8(b). Input terminals are $P_{\text {ref }}$ (desired power) and rated voltage of fuel cell $\left(\mathrm{V}_{\text {rated }}\right)$. Output terminal is $P_{e}$ which represents the electrical power output from fuel cell. This terminal is applied to $P$ input terminal of the $P Q$ inverter model.

\subsubsection{Wind Generation System Model}

Wind generator used in this paper is a squirrel-cage induction generator that directly connected to the MG. Wind turbine model is based on the steady state power characteristic of the turbine. The stiffness of the drive

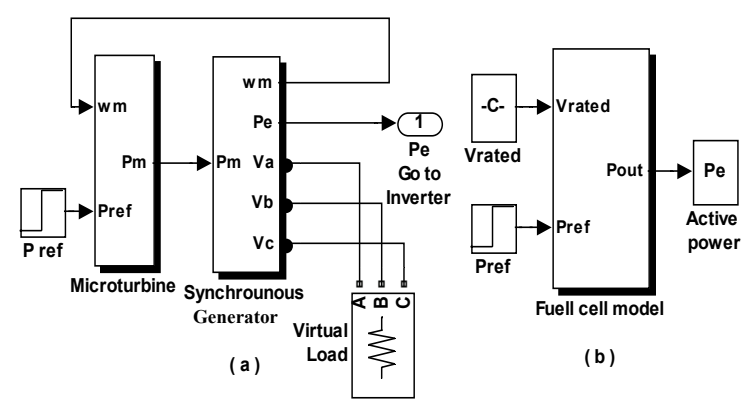

Figure 8. Micro turbine and fuel cell standalone developed models.

train is infinite and the friction factor and the inertia of the turbine must be combined with those of the generator coupled to the turbine $[14,18]$.

The output power of the turbine is given by the following equation:

$$
P_{m}=C_{P}(\lambda, \beta) \frac{\rho A}{2} v_{\text {wind }}^{3}
$$

where:

$P_{m}$ : Mechanical output power of the turbine (W).

$C_{P}$ : Performance coefficient of the turbine.

$\rho$ : Air density $\left(\mathrm{kg} / \mathrm{m}^{3}\right)$.

$v_{\text {wind }}:$ Wind speed $(\mathrm{m} / \mathrm{s})$.

$\lambda$ : Tip speed ratio of the rotor blade tip speed to wind speed.

$\beta$ : Blade pitch angle (deg.) and

$A$ : Turbine swept area $\left(\mathrm{m}^{2}\right)$.

A generic equation is used to model $C_{P}(\lambda, \beta)$. This equation, based on the modeling turbine characteristics of reference [18], is:

$$
\begin{gathered}
c_{P}(\lambda, \beta)=c_{1}\left(\frac{c_{2}}{\lambda_{i}}-c_{3} \beta-c_{4}\right) e^{\frac{-c_{5}}{\lambda_{i}}}+c_{6} \lambda \\
\text { with: } \frac{1}{\lambda_{i}}=\frac{1}{\lambda+0.08 \beta}-\frac{0.035}{\beta^{3}+1}
\end{gathered}
$$

The coefficient $C_{1}$ to $C_{6}$ are: $C_{1}=0.5176, C_{2}=116, C_{3}$ $=0.4, C_{4}=5, C_{5}=21$ and $C_{6}=0.0068$ [18].

For the induction generator, the well-known $4^{\text {th }}$ order $d q$ model is used, expressed in the arbitrary reference frame, rotating with an angular velocity $\omega$ [19]:

$$
\begin{gathered}
u_{s d}=-r_{s} \cdot i_{s d}-\omega \cdot \psi_{s q}+p \Psi_{s d} \\
u_{s q}=-r_{s} \cdot i_{s q}+\omega \cdot \psi_{s d}+p \psi_{s q} \\
u_{r d}=0=r_{r} \cdot i_{r d}-\left(\omega-\omega_{r}\right) \cdot \psi_{r q}+p \psi_{r d} \\
u_{r q}=0=r_{r} \cdot i_{r q}+\left(\omega-\omega_{r}\right) \cdot \psi_{r d}+p \psi_{r q}
\end{gathered}
$$

Where $p=\frac{1}{\omega_{0}} \frac{d}{d t}$, and $\omega_{0}$ is the base electrical angular frequency. Generator convention is used for the stator currents. The zero sequence equation is omitted, since the machine stator is connected. The stator and ro- 
tor fluxes are related to the currents by:

$$
\begin{gathered}
\psi_{s d}=-X_{s} \cdot i_{s d}+X_{m} \cdot i_{r d} \\
\psi_{s q}=-X_{s} \cdot i_{s q}+X_{m} \cdot i_{r q} \\
\psi_{r d}=-X_{m} \cdot i_{s d}+X_{r} \cdot i_{r d} \\
\psi_{r q}=-X_{m} \cdot i_{s q}+X_{r} \cdot i_{r q}
\end{gathered}
$$

The electromagnetic torque is given by:

$$
T_{e}=\psi_{q r} \cdot i_{d r}-\psi_{d r} \cdot i_{q r}
$$

The wind turbine implemented in this paper is a pitch angle controlled and directly connected to the MG with no power electronic interface. Developed wind generation system model is shown in Figure 9. The wind turbine is coupled to a squirrel cage induction generator. The input terminals of the wind turbine are wind speed $(\mathrm{m} / \mathrm{sec}$.) and pitch angle of the turbine blades (degree). The output terminal of the wind turbine is mechanical torque $\left(T_{m}\right)$ which applied to the shaft of the induction generator. The terminals of the induction generator are connected directly with the MG. In the two studied cases, the wind speed changes continuously. The values of actual wind speed are available in reference [4].

\subsubsection{Photovoltaic Panel Model.}

The $P V$ array is a grouping of $P V$ modules in series and/or in parallel, being a $P V$ module a grouping of solar cells in series and/or in parallel. In this study, Maximum Power Point Tracker (MPPT) is used to assure that the $P V$ array generates the maximum power for all irradiance and temperature values as shown in Figure 10. The whole algorithm for the computation of the maximum power of the PV under certain ambient Temperature $\left(T_{a}\right)$ and Irradiance $\left(G_{a}\right)$ is summarized in the next steps:

- The required parameters are extracted from MG parameters data base (required voltage, current and power).

- The $P V$ module's power is computed based on its dependency on Irradiance and cell Temperature as given in Equation (15) $[4,14]$.

$$
P_{\text {Max }}^{M}=\frac{G_{a}}{G_{a, o}}\left[P_{M a x, o}^{M}+\mu_{P_{M a x}}\left(T_{M}-T_{M, o}\right)\right]
$$

where:

$P_{\max }^{M}: P V$ module maximum power [W]

$P_{\text {max }, o}^{M}: P V$ module maximum power at standard conditions [W]

$G_{a, o}:$ Irradiance at standard conditions $\left[\mathrm{W} / \mathrm{m}^{2}\right]$

$\mu_{P_{M a x}}:$ Maximum power variation with module temperature $\left[\mathrm{W} /{ }^{\circ} \mathrm{C}\right]$

$T_{M}$ : Module temperature $\left[{ }^{\circ} \mathrm{C}\right]$

$T_{M, o}$ : Module temperature at standard conditions $\left[{ }^{\circ} \mathrm{C}\right]$

- The working temperature of a $P V$ module $T_{M}$ depends exclusively on the Irradiance $(G a)$ and on the ambient

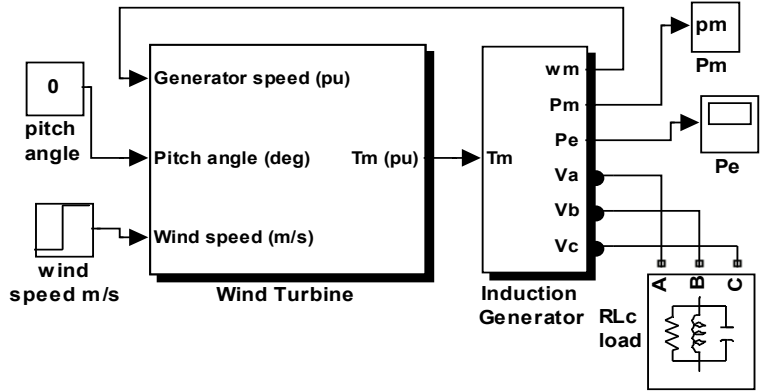

Figure 9. Wind generation system model.

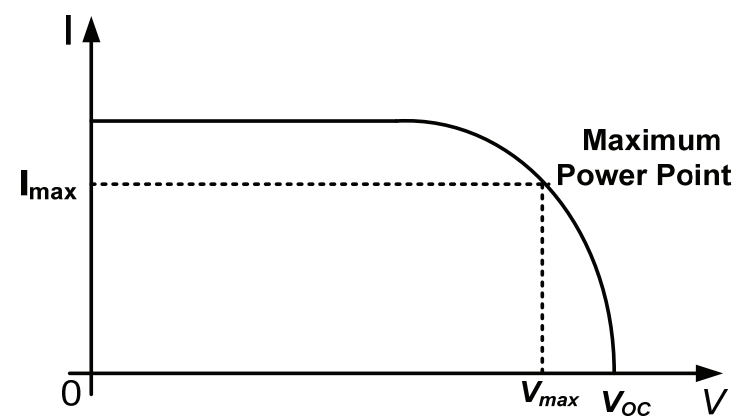

Figure 10. Typical I-V characteristics for a $P V$ array.

temperature (Ta), as shown in Equation (16) $[4,14]$ :

$$
T_{M}=T_{a}+G_{a} \cdot \frac{N O C T-20}{800}
$$

where:

$T_{M}$ : Module temperature $\left[{ }^{\circ} \mathrm{C}\right]$

$T_{a}:$ Ambient temperature $\left[{ }^{\circ} \mathrm{C}\right]$

$G_{a}:$ Irradiance $\left[\mathrm{W} / \mathrm{m}^{2}\right]$

NOCT : Normal cell operating temperature $\left[{ }^{\circ} \mathrm{C}\right]$

- Substituting Equation (16) in Equation (15) and multiplying by the number of modules of the plant, we obtain the maximum power output of the PV plant in Equation (17).

$$
P_{M a x}=N \frac{G_{a}}{1000}\left[P_{M a x, o}^{M}+\mu_{P_{M a x}} .\left(T_{a}+G_{a} \cdot \frac{N O C T-20}{800}-25\right)\right]
$$

This model is developed in Matlab ${ }^{\circledR}$ Simulink environment and shown in Figure 11. Input terminals are Irradiance $G_{a}\left[\mathrm{~W} / \mathrm{m}^{2}\right]$ and ambient temperature $T_{a}[\mathrm{Kel}-$ vin]. In the two studied cases the irradiance is assumed to change continuously and the actual values of irradiance are available in reference [4]. The output terminal is $P_{\max }$, which represents the maximum output power developed by photovoltaic panel. This terminal is applied to the input terminal of the $P Q$ inverter.

\section{Complete Model Description}

The operation of the MG with several $P Q$ inverters and a single $V f$ inverter is similar to operation of the MG with synchronous machine as a reference bus (slack bus). $V f$ 


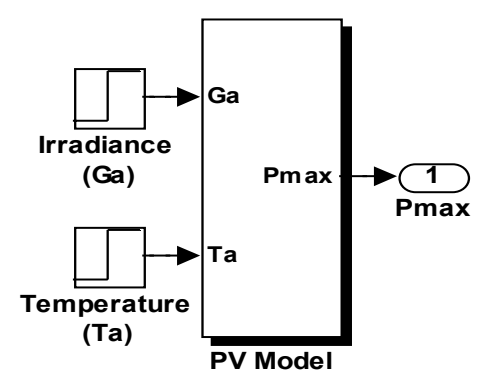

Figure 11. $P V$ array developed model.

inverter provides the voltage reference for the operation of the $P Q$ inverters when the $\mathrm{MG}$ is isolated from the main power system. Acting as a voltage source, the $V f$ inverter requires a significant amount of storage capability in the DC link or a prime power source with a very fast response in order to maintain the DC link voltage constant. In other words, the power requested by a $V f$ inverter needs to be available almost instantaneously in the DC link. In fact, this type of behavior actually models the action of the flywheel system. Flywheel was considered to be existing at the $\mathrm{DC}$ bus of the $V f$ inverter to provide the required instantaneous power. The $V f$ inverter is responsible for fast load-tracking during transients and for voltage control. During normal operation conditions (stable frequency at nominal value), the output active power of the $V f$ inverter is zero; only reactive power is injected in the MG for voltage control.

\subsection{Control of Active Power in Each Micro Source}

During islanded (autonomous) operation, when an imbalance between load and local generation occurs, the grid frequency drifts from its nominal value. Storage devices (flywheel) would keep injecting power into the network as long as the frequency differed from the nominal value. Micro turbine and fuel cell are controllable sources which their output power can be controlled. A PI controller (input of this controller is the frequency deviation) acting directly in the primary machine $\left(P_{r e f}\right.$ of fuel cell and micro turbine) allows frequency restoration. After frequency restoration, storage devices will be operating again at the normal operating point (zero active power output). This controller can not apply to wind generation system and photovoltaic panels because those micro sources are uncontrollable sources and their output power depends on weather conditions (wind speed, irradiance and ambient temperature). Figure 12 shows the PI controller block diagram used to control output power of fuel cell and micro turbine.

\subsection{Reactive Power-Voltage Control}

Figure 13 describes the adopted voltage control strategy.

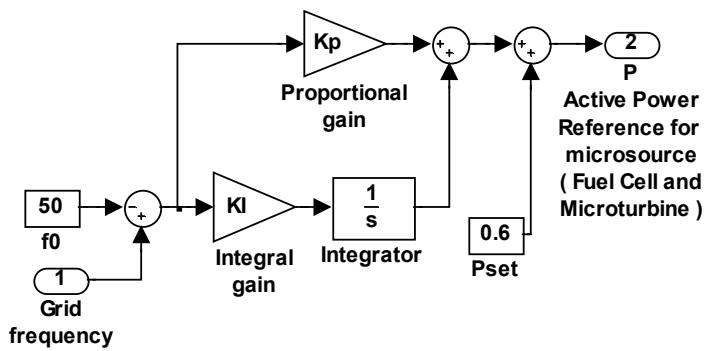

Figure 12. Control of active power of SOFC and micro turbine.

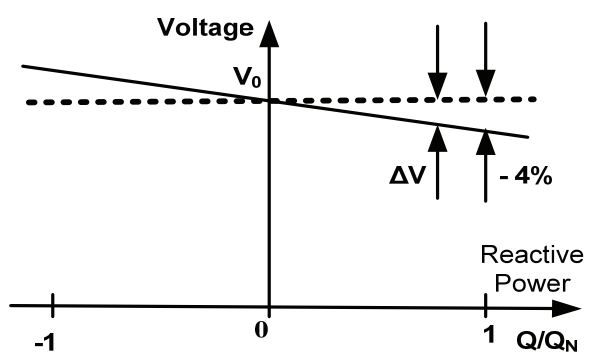

Figure 13. Droop control of the $V f$ inverter terminal voltage.

Knowing the network characteristics, it is possible to define the maximum voltage droop. To maintain the voltage between acceptable limits, $V f$ inverter connected to the flywheel will adjust the reactive power in the network. It will inject reactive power if the voltage falls under its nominal value and will absorb reactive power if the voltage rises over its nominal value.

\subsection{Active Power-Frequency Control}

The transition to islanded operation mode and the operation of the MG in islanded mode require micro generation sources to particulate in active power-frequency control, so that the generation can match the load. During this transient period, the participation of the storage devices (flywheel) in system operation is very important, since the system has very low inertia, and some micro sources (micro turbine and fuel cell) have a very slow response to the request of an increase in power generation. As already mentioned, the power necessary to provide appropriate load-following is obtained from storage devices (flywheel). Knowing the network characteristics, it becomes possible to define the maximum frequency droop as shown in Figure 14. To maintain the frequency between acceptable limits, $V f$ inverter connected to flywheel will adjust the active power in the network. It will inject active power if the frequency falls below its nominal value and will absorb active power if the frequency rises over its nominal value.

\subsection{Complete Model}

All micro sources developed models, all inverters developed 


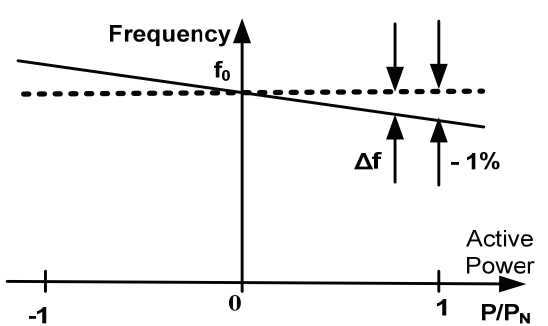

Figure 14. Frequency droop control $V f$ inverter.

models and the control strategies described in the previous sections are collected in one complete model. This model is general and can be used to describe any disturbance may be occur in the MG.

\section{Results and Discussions}

In the simulation platform, the two PV panels, the SOFC and the single shaft micro turbine are interfaced to $\mathrm{MG}$ through $P Q$ inverters. As the inverter control is quite fast and precise, it is possible to neglect the DC link voltage fluctuations; if losses are also neglected, the output active power of a $P Q$ inverter is equal to the output power of the associated micro source. Flywheel is connected to $V f$ inverter.

Case 1: MG Dynamic Performance Equipped with 10 kW Fixed Speed Wind Generation System.

In this case, amount of active power and reactive power generated from micro sources are adjusted to force $\mathrm{MG}$ imports $13 \mathrm{~kW}$ and $16 \mathrm{kVAr}$ from the main grid. Disconnection of the upstream main grid was simulated at $\mathrm{t}$ $=70$ seconds. The simulation results were presented for the main electrical quantities (frequency, voltages, active and reactive powers).

From the previous figures (Figures 15-18), the sequence of the events can be interpreted as follows:

- Before islanding occurrence, $\mathrm{MG}$ operates at its steady state and imports active and reactive powers from the main grid. Also, the frequency is at its nominal value $(50 \mathrm{~Hz})$.

- Islanding occurred at $\mathrm{t}=70$ seconds; the active power provided by main grid is lost which led to decrease in the MG frequency $(49.78 \mathrm{~Hz})$ as shown in Figure 15. Also, losing of some reactive power which was supplied by main grid forced the voltages to drop to about $97 \%$ of their nominal values as shown in Figure 16.

- The difference between load powers (active and reactive) and micro sources generated powers (active and reactive) must be compensated by $V f$ inverter connected to the flywheel as shown in Figure 17.

- Due to frequency deviation, PI controllers connected to SOFC and SSMT increases the reference powers of those micro sources. The output powers of SOFC and SSMT begin to increase and help frequency restoration

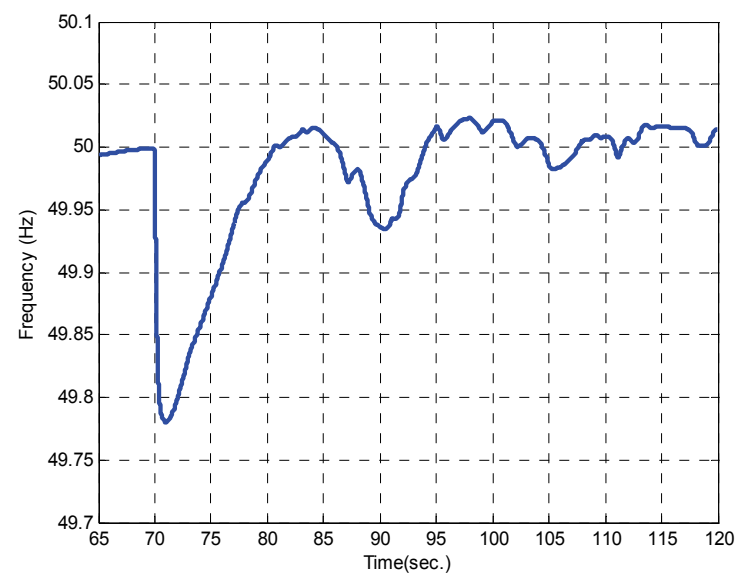

Figure 15. MG frequency before and subsequent islanding.
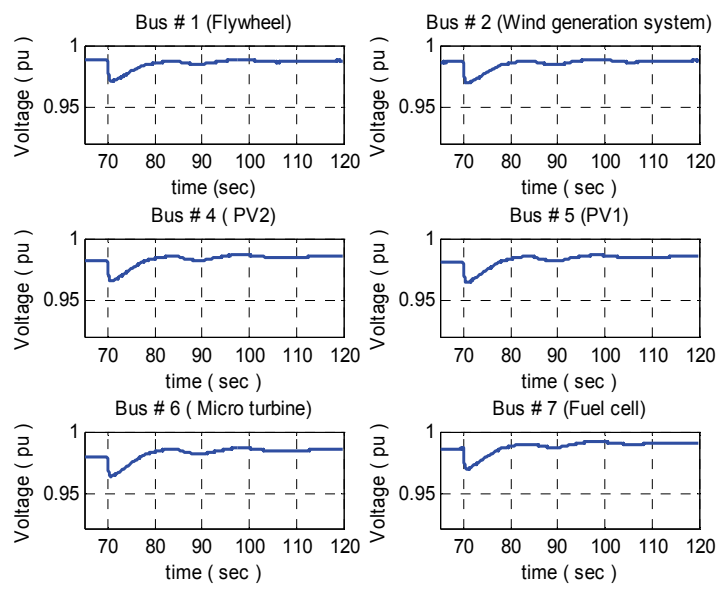

Figure 16. Voltages at all micro sources buses.

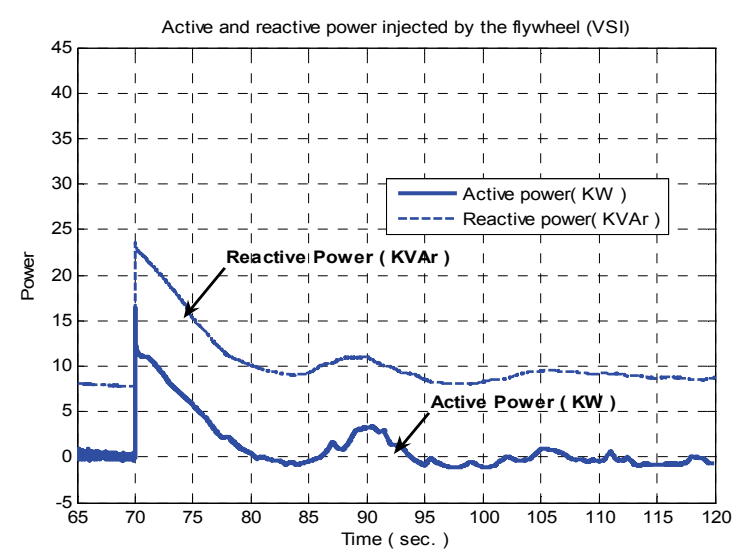

Figure 17. Flywheel ( $V f$ inverter) active and reactive powers.

\section{as shown in Figure 18.}

- Due to wind speed fluctuations, the power generated by wind generator (Squirrel cage induction generator) fluctuates which led to frequency fluctuations. Also, the reactive power absorbed by wind generator (depends 


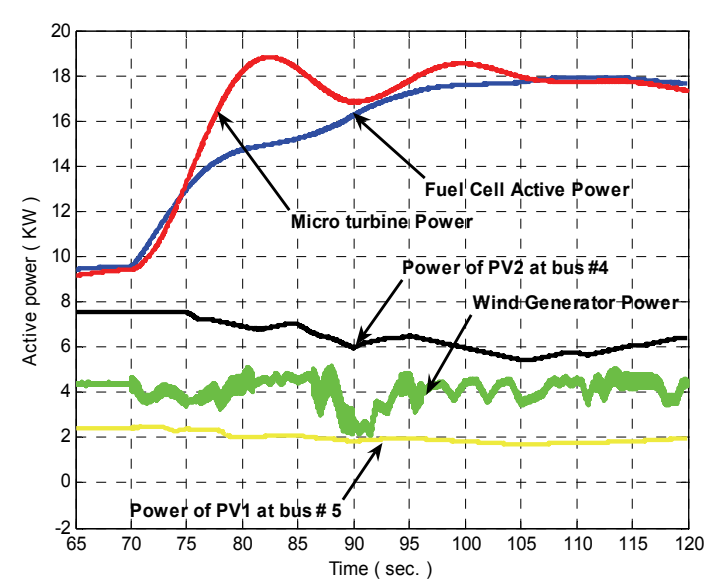

Figure 18. SOFC, SSMT, wind generator and photovoltaic panels generated active powers.

on the amount of generated active power) fluctuates which led to small flicker in voltage. The fluctuations on frequency and voltages are small because the wind generation system has small rating. The variation of photovoltaic panels' output powers is small, because the irradiance and temperature variation is less than the fluctuation of wind speed.

- Due to small rating of wind generation system, amount of reactive power injected in the MG by flywheel to keep the voltage with acceptable limits is small (less than $25 \mathrm{kVAr}$ ).

- As shown in Figure 18, the response of SSMT is faster than the response of SOFC, so that, SSMT is preferred for system needs fast dynamic response.

- After 30 seconds from islanding occurrence, amount of power produced by micro sources nearly equal to power consumed by the loads and flywheel injected power is nearly equal to zero (only small reactive power injected or absorbed by flywheel $V f$ inverter to compensate renewable sources power fluctuations).

Case 2: Dynamic Performance of MG Equipped with $30 \mathrm{~kW}$ Fixed Speed Wind Generation System.

In this case, the MG has the same conditions of the first case except the $10 \mathrm{~kW}$ fixed speed wind generation system is replaced by $30 \mathrm{~kW}$ fixed speed wind generation system. The disconnection of the upstream main grid was simulated at $\mathrm{t}=70$ seconds, and the simulation results are shown through the following figures.

From the previous figures (Figures 19-22), the following points can be summarized:

- When MG was connected to the main grid, frequency is at its nominal value $(50 \mathrm{~Hz})$. Difference between loads consumed powers and micro sources generated powers are compensated by the main grid. Active power injected by flywheel settles nearly at zero.

- When islanding occurred at $\mathrm{t}=70$ seconds, large amount of active and reactive power was lost which led to high drop in frequency $(49.74 \mathrm{~Hz})$ and voltage at all buses (94\%) as shown in Figures 19 and 20, respectively.

- To keep MG stability, flywheel $V f$ inverter must inject high amount of active and reactive powers as shown in Figure 21.

- Controllable micro sources (Fuel cell and micro turbine) increase their generated powers to help frequency restoration as shown in Figure 22.

- Due to high rating wind generation system, the fluctuations of wind speed causes high fluctuations on output power of the generator which led to high fluctuations on the MG's frequency as shown in Figure 19.

- Voltages dropped to about $94 \%$ compared with $97 \%$ in the first case.

- Amount of reactive power which must be supplied by the $V f$ inverter connected to flywheel is about 45 $\mathrm{kVAr}$ compared with $22 \mathrm{kVAr}$ only in the first case.

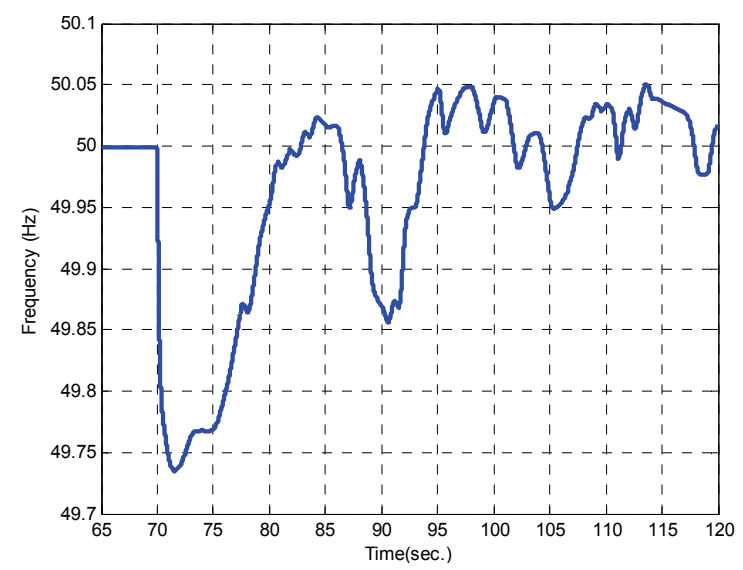

Figure 19. MG frequency.
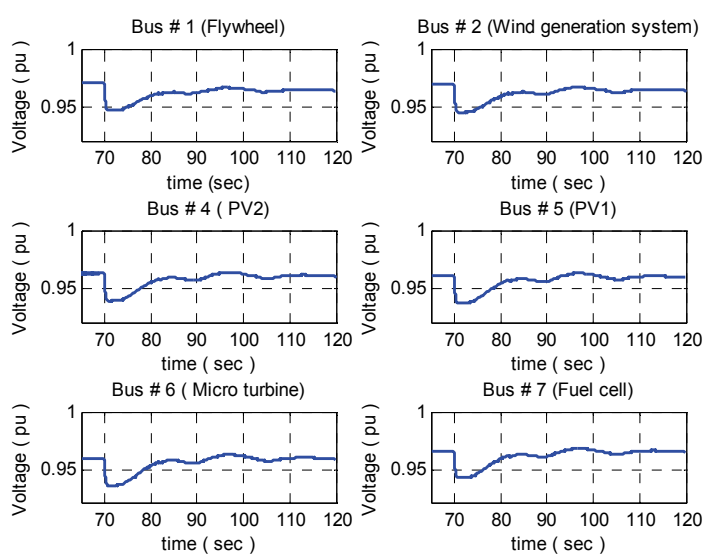

Figure 20. Voltages at all micro sources buses.

\section{Conclusions}

In this paper, the effect of increasing wind generation system rating in transient dynamic performance of the 


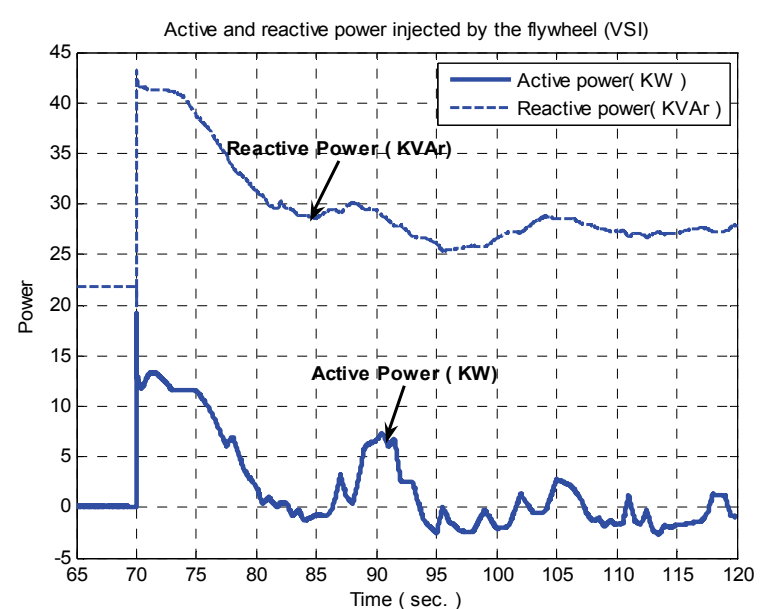

Figure 21. Flywheel ( $V f$ inverter) active and reactive powers.

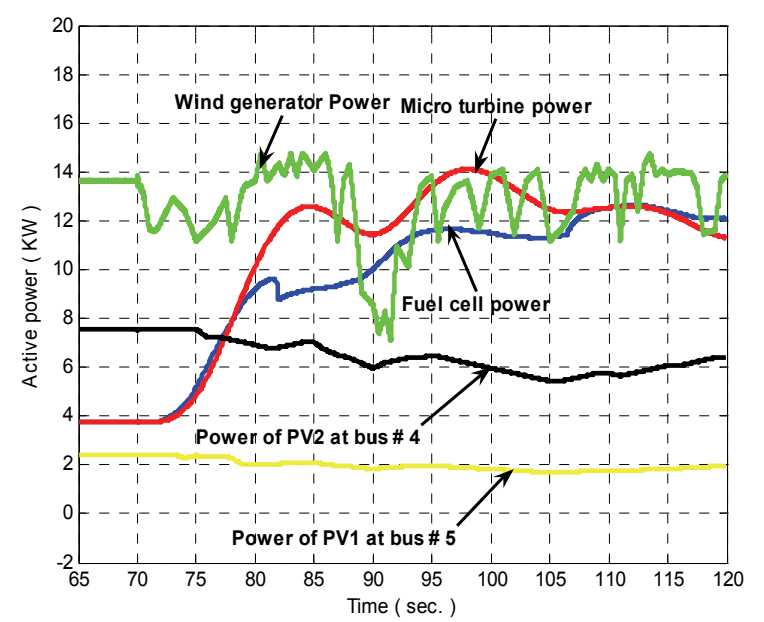

Figure 22. SOFC, SSMT, wind generator and photovoltaic panels generated active powers.

MG during and subsequent to islanding mode is investigated in details. The paper developed a complete model which can describe the dynamic performance of the $\mathrm{MG}$ at any disturbance conditions. Two cases are studied, the first case describes the transient dynamic performance of the $\mathrm{MG}$ before and subsequent to islanding occurring when the MG is equipped with $10 \mathrm{~kW}$ fixed speed wind generation system. The second case describes how the MG dynamic performance will affect if the rating of the fixed speed wind generation system is increased to 30 $\mathrm{kW}$. It is found that, increase the rating of wind generation system required more reactive power which causes high voltage drops at all buses of the MG. Also, fluctuation of wind speed causes more fluctuations in the micro grid frequency in the second case, because the power captured from the wind is proportional to the cube of the wind speed. This paper provides MG's designers with a full picture of the effect of wind generation system rating on dynamic performance of $\mathrm{MG}$ and recommends that to prevent the voltage drops with high wind power rating and keep the MG stability, MG should be equipped with adjustable reactive power compensations devices likes static VAR compensator (SVC) or static compensator (STATCOM).

\section{REFERENCES}

[1] R. Lasseter, et al., "White Paper on Integration of Distributed Energy Resources: The CERTS Micro Grid Concept," 2002. http://certs.lbl.gov/pdf/LBNL-50829.pdf

[2] European Research Project MicroGrid. http://microgrids. power.ece.ntua.gr/

[3] J. A. P. Lopes, C. L. Moreira and A. G. Madureira, "Defining Control Strategies for Micro Grids Islanded Operation," IEEE Transactions on Power System, Vol. 21, No. 2, 2006, pp. 916-924.

[4] F. D. Kanellos, A. I. Tsouchinkas and N. D. Hatziargyriouo, "Micro-Grid Simulation during Grid-Connected and Islanded Modes of Operation," International Conference on Power Systems Transients, Montreal, 2005, Paper. IPST05-113.

[5] S. Barsali, et al., "Control Techniques of Dispersed Generators to Improve the Continuity of Electricity Supply," IEEE Power Engineering Society Winter Meeting, New York, Vol. 2, 2002, pp. 789-794.

[6] F. katiraei, M. R. Irvani and P. W. Lehn, "Micro-Grid Autonomous Operation during and Subsequent to Islanding Process," IEEE Transactions on Power Delivery, Vol. 20, No. 1, 2005, pp. 248-257.

[7] R. Lasseter and P. Piagi, "Providing Premium Power through Distributed resources," Proceeding of 33rd Annual Hawaii International Conference on System Sciences, Hawaii, Vol. 4, 2000, p. 9.

[8] M. C. Chandorker, D. M. divan and R. Adapa, "Control of Parallel Connected Inverters in Standalone AC Supply System," IEEE Transactions on Industry Applications, Vol. 29, No. 1, 1993, pp. 136-143.

[9] T. Tran-Quoc, et al., "Dynamics Analysis of an Insulated Distribution Network," Proceeding of IEEE Power System Conference and Exposition, New York, Vol. 2, 2004, pp. 815-821.

[10] R. Caldon, F. Rossetto and R. Turri, "Analysis of Dynamic Performance of Dispersed Generation Connected through Inverters to Distribution Networks," Proceeding of 17th International Conference on Electricity Distribution, Barcelona, 2003, Paper 87, pp. 1-5.

[11] S. Papathanassiou, N. Hatziargyriou and K. Strunz, "A Benchmark Low Voltage Microgrid Network," Proceeding of CIGRE Symposium: Power Systems with Dispersed Generation, Athens, 2005, pp. 1-8.

[12] A. Hajimiragha, "Generation Control in Small Isolated Power Systems," Master's Thesis, Royal Institute of Technology, Department of Electrical Engineering, Stockholm, 2005. 
[13] Y. Zhu and K. Tomsovic, "Development of Models for Analyzing the Load-Following Performance of Microturbine and Fuel Cells," Electric Power System Research, Vol. 62, No. 1, 2002, pp. 1-11.

[14] G. Kariniotakis, et al., "DA1-Digital Models for Microsources," Microgrids Project Deliverable of Task DA1, 2003.

[15] L. N. Hannett, G. Jee and B. Fardanesh, "A Governor/ Turbine Model for a Twin-Shaft Combustion Turbine," IEEE Transactions on Power System, Vol. 10, No. 1, 1995, pp. 133-140.

[16] M. Nagpal, A. Moshref, G. K. morison, et al., "Experi- ence with Testing and Modeling of Gas Turbines," Proceedings of the IEEE/PES 2001 Winter Meeting, Columbus, 2001, pp. 652-656.

[17] J. Padulles, G. W. Ault and J. R. McDonald, "An Integrated SOFC Plant Dynamic Model for Power Systems Simulation," Journal of Power Sources, Vol. 86, No. 1-2, 2000, pp. 495-500.

[18] S. Heir, "Grid Integration of Wind Energy Conversion Systems," John Willy \& Sons Ltd, Kassel, 1998.

[19] C.-M. Ong, "Dynamic Simulation of Electric Machinery Using Matlab ${ }^{\circledR} /$ Simulink," Prentice Hall PTR, New Jersey, 1997. 